() OPEN ACCESS

\title{
Economic cost of smoking and secondhand smoke exposure in the Gulf Cooperation Council countries
}

\author{
Konstantina Koronaiou, ${ }^{1}$ Jawad A Al-Lawati, ${ }^{2}$ Mohamed Sayed, ${ }^{3}$ Ali M Alwadey, ${ }^{4}$ \\ Ejlal F Alalawi, ${ }^{5}$ Kholoud Almutawaa, ${ }^{6}$ Amal HJ Hussain, ${ }^{7}$ Wedad Al-Maidoor, ${ }^{8}$ \\ Yahya M Al-Farsi ${ }^{0},{ }^{9}$ Sofia Delipalla ${ }^{1}$
}

\begin{abstract}
- Additional material is published online only. To view please visit the journal online (http://dx.doi.org/10.1136/ tobaccocontrol-2020-055715).
\end{abstract}

${ }^{1}$ Department of Balkan, Slavic and Oriental Studies, School of Economic and Regional Studies, University of Macedonia, Thessaloniki 54636, Greece ${ }^{2}$ Public Health, Ministry of Health, Muscat, Oman ${ }^{3}$ Public Health, Gulf Health Council, Riyadh, Saudi Arabia ${ }^{4}$ Tobacco Control Programme, Ministry of Health, Riyadh, Saudi Arabia

${ }^{5}$ Public Health, Ministry of Health, Manama, Bahrain ${ }^{6}$ Non-Communicable Disease, Ministry of Public Health, Doha, Qatar

${ }^{7}$ Tobacco Control Programme, Ministry of Health, Kuwait City, Kuwait

${ }^{8}$ Primary Health Care, Ministry of Health, Dubai, United Arab Emirates

${ }^{9}$ Family Medicine \& Public Health, Sultan Qaboos University, Muscat, Oman

\section{Correspondence to}

Professor Sofia Delipalla, Department of Balkan, Slavic \& Oriental Studies, School of Economic and Regional Studies, University of Macedonia, Thessaloniki 54636, Greece; sd@uom.edu.gr

Received 2 March 2020 Revised 5 June 2020 Accepted 24 June 2020

D) Check for updates

(C) Author(s) (or their employer(s)) 2020. Re-use permitted under CC BY-NC. No commercial re-use. See rights and permissions. Published by BMJ.

To cite: Koronaiou K, AlLawati JA, Sayed M, et al. Tob Control Epub ahead of print: [please include Day Month Year]. doi:10.1136/ tobaccocontrol-2020-055715

\section{ABSTRACT}

Background The economic cost of smoking has been determined in many high-income countries as well as at a global level. This paper estimates the economic cost of smoking and secondhand smoke (SHS) exposure in the six Gulf Cooperation Council (GCC) countries (Bahrain, Kuwait, Oman, Qatar, Saudi Arabia and the United Arab Emirates), for which no detailed study exists.

Methods We used data from the Global Burden of Diseases Study 2016 and the cost-of-illness approach to estimate direct costs (healthcare expenditures) and indirect costs (productivity losses due to morbidity and mortality). Indirect cost was estimated with and without the inclusion of musculoskeletal disorders, using the human capital approach.

Results Total cost of smoking and SHS was estimated to be purchasing power parity (PPP)\$34.5 billion in 2016 , equivalent to $1.04 \%$ of the combined gross domestic product (GDP). SHS accounted for $20.4 \%$ of total cost. The highest proportion of indirect cost resulted from smoking in men and middle-aged people. The main causes of morbidity cost from smoking and SHS were chronic respiratory diseases and type 2 diabetes mellitus, respectively. Cardiovascular diseases were the main contributor to mortality cost for both smoking and exposure to SHS. Including musculoskeletal disorders increased total cost to PPP\$ 41.3 billion (1.25\% of the combined GDP).

Conclusion The economic cost of smoking and SHS in the GCC states is relatively low compared with other high-income countries. Scaling-up implementation of evidence-based policies will prevent the evolution of a tobacco epidemic with its negative consequences for health and public finances.

\section{INTRODUCTION}

Tobacco use is the world's leading cause of preventable morbidity and mortality and is classified as a global epidemic by the WHO and the World Bank. ${ }^{12}$ In 2019, WHO estimated that tobacco use kills more than 8 million people annually, including 1.2 million killed by exposure to secondhand smoke (SHS). ${ }^{3}$ The tobacco epidemic imposes substantial healthcare costs and loss of productivity due to morbidity and premature mortality.

Several clinical and experimental studies indicate that active smoking and SHS exposure lead to intravascular thrombosis and cardiovascular events, mainly acute coronary events, and strokes. ${ }^{4-6}$ Tobacco smoke contains more than 2500 chemical constituents, many of which are known human carcinogens. ${ }^{7}$ Chronic exposure to tobacco smoke leads to chronic inflammation and fibrosis; this, coupled with oxidative stress and an imbalance between proteases and anti-proteases enzyme secretions, leads to pathogenesis of chronic respiratory diseases. ${ }^{8}$ Compared with non-smokers, the risk of developing incident diabetes is estimated to be in excess of $37 \%$ in current smokers, $14 \%$ in former smokers and $22 \%$ for people exposed to SHS. ${ }^{9}$ Moreover, $11.7 \%$ of men and $2.4 \%$ of women cases of diabetes mellitus are attributed to smoking, and although the risk of developing it reduces after quitting smoking, it persists even 10 years after cessation. ${ }^{9}$ Several studies also relate musculoskeletal disorders to smoking. ${ }^{1011}$ Finally, digestive, neurological and eye diseases are also related to smoking along with some injuries through factors such as direct toxicity and distractibility. ${ }^{12-15}$

The economic cost of smoking has been estimated in many countries as well as at a global level. ${ }^{16}$ According to estimates from high-income countries, smoking cost ranges from $2.1 \%$ to $3.4 \%$ of the gross domestic product (GDP) in Australia, from 1.4\% to $1.9 \%$ in Canada, and $1 \%$ in the USA. ${ }^{17-19}$ A study of the economic cost of active smoking in 152 countries, of all income levels, in 2012, estimated the global average cost at $1.8 \%$ of global GDP and the average cost for high-income countries at $2.2 \% .^{20}$ Although the global study includes the Gulf Cooperation Council (GCC) countries, it focuses mainly on grouping cost estimates by country income level and WHO region.

The GCC is a political and economic alliance of six high-income countries, namely, Saudi Arabia, Kuwait, the United Arab Emirates, Qatar, Bahrain and Oman. They share similar political and cultural identities, rooted in Arab and Islamic cultures. All six states share same religion, language, geography, as well as past colonial background.

In the absence of any significant form of manufacturing tobacco products locally, import data in all GCC countries show that cigarettes are the most imported form of tobacco products. ${ }^{21}$ Cigarettes are the most used product, although waterpipe tobacco is also used. ${ }^{22}$ The age-standardised prevalence of daily tobacco smoking is close to or below the world average, at 25\% in men and 5.4\% in women. ${ }^{23}$ Kuwait reported the highest smoking prevalence for men (23.2\%), while the highest among women was in Bahrain (6.2\%). ${ }^{23}$ The daily smoking prevalence is expected to increase by 2025 in all GCC countries except Kuwait. ${ }^{24}$

To the best of our knowledge, there are no studies that focus specifically on estimating the economic 
burden of tobacco use in the GCC countries. Apart from the global study, ${ }^{20}$ with a brief reference to the GCC, there is also a study specific to Saudi Arabia, estimating the cost of tobacco use for the period 2001-2010. ${ }^{25}$ Neither study, however, shows how the cost of smoking is distributed in the population and among related diseases. Moreover, no study has yet estimated the economic cost of SHS in these countries. Thus, we embarked on this study to estimate the direct and indirect costs of both active smoking and SHS exposure in the GCC countries, by gender, age and disease, using data from the 2016 Global Burden of Diseases Study (GBD), and including a larger number of smoking-related diseases than in most cost studies.

\section{METHODS}

The methods used were based on WHO toolkit ${ }^{26}$ on the economic cost of smoking, which adopts the cost-of-illness approach to estimate direct and indirect costs. ${ }^{27}{ }^{28}$ Direct costs are related to healthcare costs (hospitalisations, outpatient visits, medications and so on) and non-healthcare costs (caregiving by non-health providers, expenses to replace sick smokers and so on). Indirect costs measure productivity losses due to morbidity and premature mortality caused by diseases related to smoking and SHS exposure.

Owing to lack of data, we estimated the direct cost $\left(\mathrm{SHE}_{s}\right)$ focusing only on healthcare costs, using the following formula:

$$
\mathrm{SHE}_{\mathrm{s}}=\mathrm{SAF} \times \mathrm{THE}_{\mathrm{s}}
$$

where SAF is smoking-attributable fraction (proportion of healthcare spending attributable to smoking and SHS exposure) and $\mathrm{THE}_{\mathrm{s}}$ is the total national annual healthcare spending by financing source (health spending by government, out-of-pocket health expenditure and prepaid private spending).

The indirect cost was estimated using the human capital approach followed in most studies. Compared with the alternatives (friction cost method and willingness to pay approach), the value of estimated cost lies in between. ${ }^{20}$ The indirect costs of both morbidity and mortality were estimated by gender, age and disease. Costs were calculated for ages 30-69 years for smoking and 15-69 years for SHS. The age of 15 is the minimum legal working age, while the age of 30 was selected as the minimum age owing to the latency between exposure to tobacco and its smoke and the appearance of health consequences. ${ }^{26}$ The age of 69 was selected for comparison purposes, as selected by Goodchild et al. ${ }^{20}$ We included all diseases (online supplementary table S1) for which tobacco-attributable deaths and disability were estimated by the Institute of Health Metrics and Evaluation (IHME), ${ }^{29}$ excluding initially musculoskeletal disorders as their inclusion is not a common practice. ${ }^{203031}$ However, for comparison purposes, we also estimated the economic cost of smoking and SHS including musculoskeletal diseases.

Morbidity cost (MRBC) caused by smoking/SHS-attributable disease $i$, among a population with gender $g$ and age $a$, was calculated as:

$$
\mathrm{MRBC}_{\text {iga }}=\mathrm{SAF}_{\text {iga }} \times \mathrm{YLD}_{\text {iga }} \times \mathrm{EMP}_{\text {ga }} \times \mathrm{PROD}
$$

where $\mathrm{SAF}_{i g a}$ is smoking-attributable fraction of morbidity cost and $\mathrm{YLD}_{i g a}$ is the number of years lost to disability caused by disease $i$, among a population with gender $g$ and age $a$. $\mathrm{EMP}_{g a}$ is employment-to-population ratio for population with gender $g$ and age $a$. PROD is the amount of GDP per worker, calculated by dividing national GDP by total employment. The product of the first two components is the number of years lost to disability caused by diseases related to smoking and SHS exposure. To estimate productivity losses, we multiplied these years with the proportion of population being employed and the product generated by the worker.

Mortality cost (MRTC) caused by smoking/SHS-attributable disease $i$, among a population with gender $g$ and age $a$, was calculated as:

$$
\text { MRTC }_{\text {iga }}=\mathrm{SAF}_{\text {iga }} \times \sum_{\mathrm{d}=\text { MINd }}^{\text {MAXd }}\left(\text { TDEATH }_{\text {igad }} \times \text { PVLE }_{\text {gad }}\right)
$$

where $\mathrm{SAF}_{\text {iga }}$ is smoking-attributable fraction of deaths from a disease $i$, among a population with gender $g$ and age $a$. TDEATH is the total number of deaths from disease $i$, and PVLE gad $_{\text {iga }}$ is the total discounted present value of lifetime earnings for population of gender $g$ and age $a$, whose age at death is within the 5-year age group ' $d$ '. $\mathrm{MIN}_{d}$ and $\mathrm{MAX}_{d}$ are minimum and maximum age group, the age of 30 and 69, respectively. The PVLE is calculated based on the approach developed by Max and colleagues ${ }^{32}$ and used by others. ${ }^{33}$ For the calculation of PVLE, we used GDP per worker as earnings, without taking into account the value of housekeeping services. We assumed $1 \%$ annual productivity growth and non-discounting for human life. ${ }^{32}$ However, we also calculated costs assuming a discount rate of $3 \%$, which used to be a common practice in such studies. ${ }^{34}$

\section{Data sources}

Our primary data source was the GBD, coordinated by the IHME. $^{29}$ The retrieved data were total national annual healthcare expenditure by financing source, ${ }^{35}$ estimated SAFs for active smoking and SHS exposure, YLD, and number of deaths by gender, age group, and disease. ${ }^{29}$ Online supplementary tables S2-S9 present YLD and deaths related to active smoking and SHS exposure.

Data on GDP were obtained from the October 2018 World Economic Outlook Database provided by the International Monetary Fund (IMF), ${ }^{36}$ and life tables were obtained from the WHO database. ${ }^{37}$ The number of workers and employment-topopulation ratio were provided from each country's national sources, when available, or from the International Labour Organization. ${ }^{38}$ Costs are reported in international dollars using the IMF purchasing power parity (PPP) conversion rates for 2016, to capture price differences among countries. ${ }^{36}$ Key findings are also reported in US dollar (US\$).

\section{RESULTS}

Overall, total cost of smoking and SHS exposure amounted to approximately PPP\$ 34.5 (US\$14.3) billion for all six countries together (table 1). This was equal to $1.04 \%$ of their combined GDP and ranged from $0.59 \%$ in Qatar to $1.45 \%$ in Kuwait. The per capita cost was lowest in Oman (PPP\$ 412) and highest in Kuwait (PPP\$ 985). At the GCC level, the cost of SHS accounted for $20.4 \%$ of total cost of smoking and SHS, and varied from $18.5 \%$ in the UAE to $25.4 \%$ in Bahrain.

\section{Economic cost of active smoking}

At the GCC level, total cost of active smoking was PPP\$ 27 463 (US\$11 399) million (table 2 and online supplementary table S10). As a percentage of the combined GDP, total cost of smoking amounted to $0.83 \%$. Of this, direct cost accounted for $39.5 \%$ (PPP\$ 10852 million or US\$4424 million). Countryspecific data revealed that direct cost was higher than morbidity and mortality cost across all countries, except for the UAE where mortality cost was the highest of all. The direct cost constituted $0.33 \%$ of the total GDP (table 2).

The lowest percentage of deaths related to smoking (smokingattributable deaths, SAD) was in Saudi Arabia (5.9\%) and the 
Table 1 Total economic cost of smoking and secondhand smoke exposure by country, 2016

\begin{tabular}{|c|c|c|c|c|c|}
\hline \multirow[b]{2}{*}{ Country } & \multicolumn{4}{|c|}{ Total cost of smoking and SHS } & \multirow{2}{*}{$\begin{array}{l}\text { Cost of SHS } \\
\% \text { of total } \\
\text { cost }\end{array}$} \\
\hline & $\begin{array}{l}\text { US\$ } \\
\text { (million) }\end{array}$ & $\begin{array}{l}\text { PPP\$ } \\
\text { (million) }\end{array}$ & $\begin{array}{l}\text { Per capita } \\
\text { PPP\$ }\end{array}$ & $\%$ of GDP & \\
\hline Bahrain & 456 & 951 & 668 & 1.41 & 25.4 \\
\hline Kuwait & 1609 & 4267 & 985 & 1.45 & 19.2 \\
\hline Oman & 637 & 1818 & 412 & 0.97 & 22.9 \\
\hline Qatar & 895 & 1935 & 739 & 0.59 & 24.3 \\
\hline KSA & 6309 & 17191 & 541 & 0.98 & 20.7 \\
\hline UAE & 4401 & 8352 & 916 & 1.23 & 18.5 \\
\hline All & 14307 & 34514 & 643 & 1.04 & 20.4 \\
\hline
\end{tabular}

highest in Kuwait (13.6\%). The analysis of the direct cost by financing source shows that, for all GCC countries, the highest percentage of direct cost was government health spending, followed by out-of-pocket spending and prepaid private spending (figure 1). Across the countries, out-of-pocket spending was higher than prepaid private spending, except in Qatar where prepaid spending was higher.

The overall indirect cost of active smoking was estimated at PPP\$ 16611 million. Of total indirect cost, morbidity cost was $36.7 \%$ (PPP\$ 6089 million), while mortality cost was 63.3\% (PPP\$ 10522 million). Among the three types of costs, morbidity cost was the lowest, except for Bahrain and Qatar where mortality cost was the lowest (table 2).

Generally, the distribution of indirect cost categories resembled a bell-shaped curve (figure 2). At GCC level, morbidity cost raised steadily with age, until the age group 40-44 after which it declined. Similarly, mortality cost raised steadily, and peaked at age group 45-49. More than half of active smoking-attributable morbidity and mortality costs resulted from working adults aged $35-49$ and 40-54 years, respectively.

The proportion of morbidity cost among women was higher than the corresponding proportion of mortality cost across all countries (online supplementary figure S1). Both indirect cost categories, however, were extremely low for women $(0.8 \%-$ $3.6 \%$ for morbidity and $0.3 \%-1.7 \%$ for mortality cost).

Almost all morbidity and mortality costs were caused by noncommunicable diseases (table 3). The main cause of smokingattributable morbidity cost was chronic respiratory diseases (37.1\%), followed by type 2 diabetes mellitus (T2DM) (32.7\%) and cardiovascular diseases (CVDs) (21\%). CVD (mainly ischaemic heart disease) accounted for $59.4 \%-81.8 \%$ of mortality cost due to active smoking, followed by malignant neoplasms $(10.2 \%-20.8 \%)$. Results by gender and age are presented in online supplementary tables S11-S12 (online supplementary file).

\section{Economic cost of SHS}

Total cost of SHS exposure was approximately PPP\$ 7.1 billion $(0.21 \%$ of the combined GDP) (table 2 and online supplementary table S10). Direct cost was estimated at PPP\$ 2866 or US $\$ 1150$ million, equalling $40.6 \%$ of the total cost of SHS, while the proportions of morbidity and mortality costs were $33.4 \%$ and $25.9 \%$, respectively.

Country-specific data showed that, among the three types of costs of SHS, direct cost was the highest, except for Qatar and the UAE where morbidity cost was the highest. As a percentage of GDP, overall direct cost was $0.09 \%$, while cost of morbidity was $0.07 \%$ (PPP\$ 2357 million) and that of mortality $0.06 \%$ (PPP\$ 1828 million). Among the three types of costs, mortality cost was the lowest, except for the UAE where direct cost was the lowest.

The analysis of the indirect cost of SHS exposure by gender and age group showed a similar pattern to that of active smoking with some variations. The proportion of mortality cost resulting from women was lower than the corresponding proportion of morbidity cost (online supplementary figure $\mathrm{S} 1$ ). The proportion of both morbidity and mortality costs among women were much lower than those among men, although higher compared with the corresponding proportions related to active smoking. At the GCC level, $22.2 \%$ of morbidity cost and $9.4 \%$ of mortality cost were among women. The distributions of indirect costs of exposure to SHS over age categories were also bell-shaped, similar to active smoking curves. The peak of mortality cost was in the age group 45-49. The peak of morbidity cost, however,

Table 2 Direct and indirect cost of smoking and secondhand smoke exposure, by country, 2016

\begin{tabular}{|c|c|c|c|c|c|c|c|c|c|c|c|c|c|c|c|c|}
\hline \multirow[b]{2}{*}{ Country } & \multicolumn{5}{|c|}{ Direct cost } & \multicolumn{4}{|c|}{ Morbidity cost } & \multicolumn{4}{|c|}{ Mortality cost } & \multicolumn{3}{|l|}{ Total cost } \\
\hline & $\begin{array}{l}\text { SAD } \\
(\%)\end{array}$ & $\begin{array}{l}\text { PPP\$ } \\
\text { (million) }\end{array}$ & $\begin{array}{l}\text { Per capita } \\
\text { PPP\$ }\end{array}$ & $\begin{array}{l}\% \text { of } \\
\text { GDP }\end{array}$ & $\begin{array}{l}\% \text { of total } \\
\text { cost }\end{array}$ & $\begin{array}{l}\text { PPP\$ } \\
\text { (million) }\end{array}$ & $\begin{array}{l}\text { Per capita } \\
\text { PPP\$ }\end{array}$ & $\begin{array}{l}\% \text { of } \\
\text { GDP }\end{array}$ & $\begin{array}{l}\% \text { of total } \\
\text { cost }\end{array}$ & $\begin{array}{l}\text { PPP\$ } \\
\text { (million) }\end{array}$ & $\begin{array}{l}\text { Per capita } \\
\text { PPP\$ }\end{array}$ & $\begin{array}{l}\% \text { of } \\
\text { GDP }\end{array}$ & $\begin{array}{l}\% \text { of total } \\
\text { cost }\end{array}$ & $\begin{array}{l}\text { PPP\$ } \\
\text { (million) }\end{array}$ & $\begin{array}{l}\text { Per capita } \\
\text { PPPS }\end{array}$ & $\begin{array}{l}\% \text { of } \\
\text { GDP }\end{array}$ \\
\hline \multicolumn{17}{|l|}{ Smoking } \\
\hline Bahrain & 9.7 & 333 & 234 & 0.49 & 46.9 & 196 & 137 & 0.29 & 27.6 & 181 & 127 & 0.27 & 25.5 & 710 & 498 & 1.05 \\
\hline Kuwait & 13.6 & 1397 & 323 & 0.48 & 40.5 & 725 & 167 & 0.25 & 21.0 & 1325 & 306 & 0.45 & 38.4 & 3447 & 796 & 1.17 \\
\hline Oman & 8.2 & 633 & 144 & 0.34 & 45.2 & 315 & 71 & 0.17 & 22.5 & 453 & 103 & 0.24 & 32.3 & 1401 & 318 & 0.74 \\
\hline Qatar & 7.2 & 532 & 203 & 0.16 & 36.3 & 485 & 185 & 0.15 & 33.1 & 448 & 171 & 0.14 & 30.6 & 1465 & 560 & 0.45 \\
\hline KSA & 5.9 & 5774 & 182 & 0.33 & 42.4 & 2685 & 84 & 0.15 & 19.7 & 5173 & 163 & 0.29 & 37.9 & 13632 & 429 & 0.78 \\
\hline UAE & 9.1 & 2183 & 239 & 0.32 & 32.1 & 1682 & 184 & 0.25 & 24.7 & 2941 & 322 & 0.43 & 43.2 & 6807 & 746 & 1.00 \\
\hline All & & 10852 & 202 & 0.33 & 39.5 & 6089 & 113 & 0.18 & 22.2 & 10522 & 196 & 0.32 & 38.3 & 27463 & 511 & 0.83 \\
\hline \multicolumn{17}{|l|}{ SHS } \\
\hline Bahrain & 3.1 & 108 & 76 & 0.16 & 44.6 & 87 & 61 & 0.13 & 35.8 & 47 & 33 & 0.07 & 19.6 & 242 & 170 & 0.36 \\
\hline Kuwait & 3.2 & 333 & 77 & 0.11 & 40.6 & 252 & 58 & 0.09 & 30.7 & 235 & 54 & 0.08 & 28.7 & 819 & 189 & 0.28 \\
\hline Oman & 2.4 & 190 & 43 & 0.10 & 45.6 & 117 & 26 & 0.06 & 28.0 & 110 & 25 & 0.06 & 26.3 & 416 & 94 & 0.22 \\
\hline Qatar & 1.9 & 145 & 55 & 0.04 & 30.8 & 227 & 87 & 0.07 & 48.4 & 98 & 37 & 0.03 & 20.8 & 470 & 179 & 0.14 \\
\hline KSA & 1.7 & 1643 & 52 & 0.09 & 46.2 & 1065 & 34 & 0.06 & 29.9 & 851 & 27 & 0.05 & 23.9 & 3559 & 112 & 0.20 \\
\hline UAE & 1.9 & 448 & 49 & 0.07 & 29.0 & 610 & 67 & 0.09 & 39.5 & 487 & 53 & 0.07 & 31.5 & 1545 & 169 & 0.23 \\
\hline All & & 2866 & 53 & 0.09 & 40.6 & 2357 & 44 & 0.07 & 33.4 & 1828 & 34 & 0.06 & 25.9 & 7051 & 131 & 0.21 \\
\hline
\end{tabular}

GDP, gross domestic product; KSA, Kingdom of Saudi Arabia; PPP\$, purchasing power parity dollars using international Monetary Fund 2016 conversion rates; SAD, smoking attributable deaths; SHS, secondhand smoke; UAE, United Arab Emirates. 


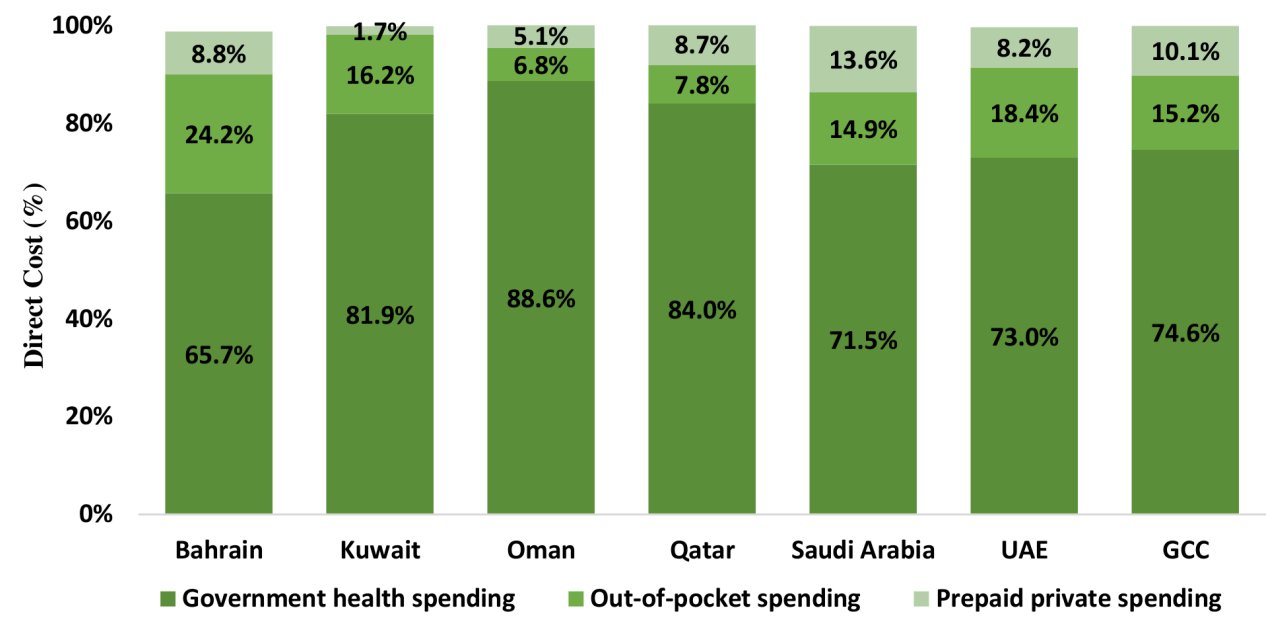

Figure 1 Direct cost of smoking (\%) by source of expenditure and by country, 2016. UAE, United Arab Emirates; GCC, Gulf Cooperation Council.

occurred in a younger age group (35-39) compared with active smoking (figure 2). Table 3 indicates that the highest proportion of morbidity due to SHS exposure was attributed to T2DM (72.7\%), followed by chronic respiratory diseases (22.2\%). These two causes were responsible for almost all morbidity cost due to SHS exposure, while CVD was the leading cause of mortality cost due to SHS exposure in all GCC countries, accounting for $7 \%$ of all mortality cost.

\section{Sensitivity analysis}

Applying a discount rate of $3 \%$ for mortality cost estimation led to $8.3 \%$ reduction in total cost of smoking and SHS exposure, amounting to $0.96 \%$ of the combined GDP, with a $23.3 \%$ reduction in the cost of mortality (online supplementary table S13).

Including musculoskeletal disorders into our analysis resulted in the total cost of active smoking and SHS to be increased to PPP\$ 41.3 billion (1.25\% of GDP), with musculoskeletal disorders becoming the main cause of smoking-attributed morbidity (online supplementary tables S14 and S15). This happens because a lot of people suffer from a musculoskeletal disorder and, in most cases, this is a chronic disease.

\section{DISCUSSION}

This is the first comprehensive study on the cost of active smoking and SHS exposure in the GCC countries. It confirms that smoking imposes a significant toll on these countries with a staggering total cost of over PPP\$ 34 billion, amounting to $1.04 \%$ of the value of all goods and services produced in the six GCC nations combined.

The main analysis shows that total cost of smoking and SHS, as a percentage of GDP, was highest in Bahrain and Kuwait (around 1.4\%), draining higher than the average portion of GDP $(1.04 \%)$. This could be due to higher rates of current tobacco use in both Kuwaiti and Bahraini men (>40\%) and women (8.6\% and $3.4 \%$, respectively) compared with the other four nations ( $\leq 32 \%$ among men and $\leq 2 \%$ among women). ${ }^{39}$ Early oil discovery in Kuwait and Bahrain has led to an increase in disposable income, which may be related to the relatively higher prevalence of tobacco consumption compared with the other GCC countries. ${ }^{40}$

Globally, smoking-related health expenditures and productivity losses account for $1.8 \%$ of the world's GDP. ${ }^{20}$ The estimated cost of smoking and SHS as a fraction of GDP (1.04\%) in the GCC countries was lower than that reported for other high-income countries, such as Australia (2.1\% to 3.4\%), Canada $(1.4 \%$ to $1.9 \%)$ and Greece $(3.4 \%)$, but similar to estimates from the USA (1.0\%). ${ }^{17-19} 33$ However, it must be noted that these studies, except for that of Greece, did not include the cost of SHS. In contrast, the cost of smoking, as a percentage of GDP, has been reported to be lower in middle-income countries, such as China $(0.7 \%)$, Uganda $(0.5 \%)$ and Iran $(0.26 \%) .{ }^{19} 4142$ The relatively low cost of smoking in the GCC could be due to

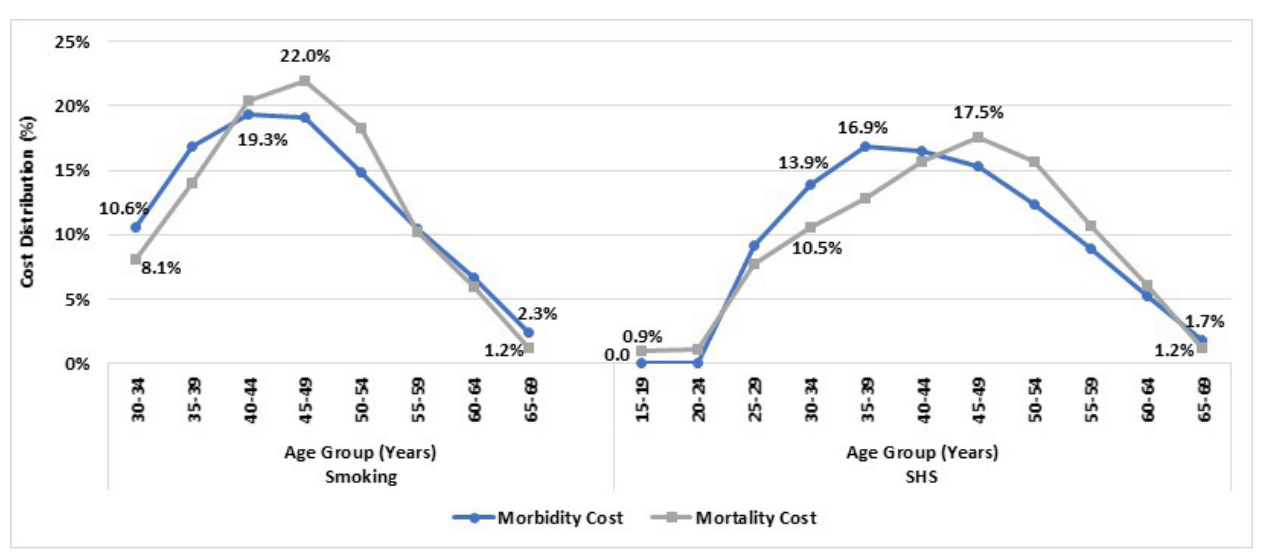

Figure 2 Indirect cost of smoking and secondhand smoke (SHS) exposure, percentage distribution by age group, Gulf Cooperation Council countries, 2016. 
Table 3 Morbidity and mortality cost distribution (\%) by cause of disease, ages 30-69 (smoking) and 15-69 (SHS), both genders, GCC countries, 2016

\begin{tabular}{|c|c|c|c|c|c|c|c|c|c|c|c|c|c|c|}
\hline & \multicolumn{7}{|c|}{ Morbidity cost (\%) } & \multicolumn{7}{|c|}{ Mortality cost (\%) } \\
\hline & BHR & KWT & OMN & QTR & KSA & UAE & ALL & BHR & KWT & $\mathrm{OMN}$ & QTR & KSA & UAE & ALL \\
\hline \multicolumn{15}{|l|}{ Smoking } \\
\hline A. Communicable diseases & 0.6 & 0.7 & 0.7 & 0.7 & 1.1 & 0.6 & 0.8 & 4.2 & 4.8 & 5.1 & 4.8 & 7.6 & 3.8 & 5.9 \\
\hline Respiratory infections and tuberculosis & 0.6 & 0.7 & 0.7 & 0.7 & 1.1 & 0.6 & 0.8 & 4.2 & 4.8 & 5.1 & 4.8 & 7.6 & 3.8 & 5.9 \\
\hline B. Non-communicable diseases & 98.4 & 98.0 & 98.3 & 97.8 & 96.9 & 98.0 & 97.5 & 95.4 & 94.7 & 93.9 & 93.8 & 90.9 & 94.9 & 92.8 \\
\hline Neoplasms & 1.0 & 1.1 & 1.1 & 1.1 & 1.5 & 1.4 & 1.4 & 18.2 & 10.3 & 12.2 & 20.9 & 12.7 & 17.6 & 14.2 \\
\hline Cardiovascular diseases & 18.9 & 20.5 & 22.2 & 19.0 & 24.3 & 16.9 & 21.1 & 65.3 & 81.8 & 77.9 & 65.7 & 73.6 & 59.4 & 70.4 \\
\hline Chronic respiratory diseases & 38.6 & 36.9 & 30.5 & 35.7 & 31.2 & 47.9 & 37.1 & 2.8 & 1.2 & 1.0 & 2.3 & 2.8 & 15.3 & 6.0 \\
\hline Digestive diseases & 1.8 & 1.9 & 2.3 & 3.1 & 2.5 & 1.8 & 2.3 & 0.4 & 0.3 & 0.3 & 0.4 & 0.2 & 0.4 & 0.3 \\
\hline Neurological disorders & 0.8 & 0.9 & 0.7 & 0.7 & 0.7 & 0.7 & 0.7 & 0.6 & 0.4 & 0.4 & 0.6 & 0.4 & 0.4 & 0.4 \\
\hline Type 2 diabetes mellitus & 35.2 & 34.1 & 35.5 & 36.4 & 34.2 & 27.7 & 32.7 & 8.1 & 0.9 & 2.1 & 3.9 & 1.2 & 1.8 & 1.6 \\
\hline Sense organ diseases & 2.1 & 2.6 & 6.1 & 1.8 & 2.3 & 1.6 & 2.3 & & & & & & & \\
\hline C. Injuries & 1.1 & 1.4 & 1.0 & 1.6 & 2.1 & 1.5 & 1.7 & 0.4 & 0.4 & 1.0 & 1.5 & 1.5 & 1.4 & 1.3 \\
\hline \multicolumn{15}{|l|}{ SHS } \\
\hline A. Communicable diseases & 0.4 & 0.6 & 0.9 & 0.5 & 0.4 & 0.3 & 0.4 & 6.4 & 11.8 & 12.0 & 9.9 & 10.4 & 5.2 & 9.2 \\
\hline Respiratory infections and tuberculosis & 0.4 & 0.6 & 0.9 & 0.5 & 0.4 & 0.3 & 0.4 & 6.4 & 11.8 & 12.0 & 9.9 & 10.4 & 5.2 & 9.2 \\
\hline B. Non-communicable diseases & 99.6 & 99.4 & 99.1 & 99.5 & 99.6 & 99.7 & 99.6 & 93.6 & 88.2 & 88.0 & 90.1 & 89.6 & 94.8 & 90.8 \\
\hline Neoplasms & 0.2 & 0.3 & 0.1 & 0.2 & 0.2 & 0.2 & 0.2 & 5.3 & 4.1 & 2.2 & 6.3 & 2.5 & 3.3 & 3.2 \\
\hline Cardiovascular diseases & 4.0 & 5.3 & 5.1 & 3.7 & 4.4 & 4.2 & 4.4 & 61.5 & 79.5 & 79.0 & 66.0 & 78.0 & 66.3 & 74.1 \\
\hline Chronic respiratory diseases & 27.4 & 30.3 & 22.1 & 23.5 & 16.0 & 28.5 & 22.2 & 2.2 & 1.6 & 0.6 & 2.9 & 2.6 & 16.2 & 6.0 \\
\hline Type 2 diabetes mellitus & 68.0 & 63.4 & 71.7 & 72.0 & 78.9 & 66.9 & 72.7 & 24.5 & 3.0 & 6.2 & 14.9 & 6.4 & 8.9 & 7.6 \\
\hline
\end{tabular}

BHR, Bahrain; GCC, Gulf Cooperation Council; KSA, Kingdom of Saudi Arabia; KWT, Kuwait; OMN, Oman; QTR, Qatar; SHS, secondhand smoke; UAE, United Arab Emirates.

extremely low rates of current tobacco use in women $(<1 \%$ in Oman and the UAE and $\leq 2 \%$ in Qatar and Saudi Arabia) and low employment rates in women. ${ }^{39} 43$

The direct cost accounted for $40 \%$ of total cost, compared with $24 \%$ for morbidity and $36 \%$ for mortality. The corresponding figures reported for Sweden were 26\%, 21\% and 53\%; for China 34\%, 8\% and 58\%; for Vietnam 50.5\%, 10.7\% and $38.7 \%$; and for Iran $28.2 \%, 1.7 \%$ and $70 \%$, respectively. ${ }^{42} 44-46$ Although studies used different methods and time periods to compute costs, morbidity cost accounted for a lower proportion in all of them.

Results by country showed that, for smoking, the highest cost is the direct cost, except for the UAE where mortality cost is the highest. This can be explained by UAE's high death rates compared with other countries. ${ }^{29}$ On the other hand, Bahrain and Kuwait had the lowest death rates; as a result, mortality cost was the lowest among the three types of cost. Direct cost is the highest also for SHS except for Qatar and the UAE, where morbidity cost was the highest. This is due to the high rates of YLD in the UAE and the high GDP/worker and employment-topopulation ratio in Qatar.

SHS exposure imposes a significant cost on GCC nations, with $20.9 \%$ of direct and $20.1 \%$ of indirect costs attributed to SHS exposure. These figures are more than double the cost reported for Greece (9.9\% for direct and 8.1\% for indirect cost) and Taiwan ( $8 \%$ of the total cost). ${ }^{3347}$ Until a decade ago, almost all GCC countries had no regulations banning smoking in indoor public places. ${ }^{48} 49$ The GCC countries introduced tobacco control legislation relatively recently (Bahrain 2009, Oman 2010, Saudi Arabia 2015, Kuwait 2014, UAE 2009, Qatar 2002). ${ }^{48} 49$ Two studies, for Bahrain and Oman, reported high levels of fine particulate matters sized 2.5 microns $\left(\mathrm{PM}_{25}\right)$ in recreational venues $\left(200 \mu \mathrm{g} / \mathrm{m}^{3}\right.$ in Bahrain and $256 \mu \mathrm{g} / \mathrm{m}^{3}$ in Oman), 10 times the acceptable limits suggested by WHO for a whole day $\left(25 \mu \mathrm{g} / \mathrm{m}^{3}\right){ }^{5051}$
CVDs are the leading cause of death in all GCC countries. ${ }^{52}$ This study showed that $70.4 \%$ of the total smoking-attributable mortality cost is due to CVD, followed by malignant neoplasms $(14.2 \%)$ and chronic respiratory diseases (6\%). A similar pattern was reported for Sweden, Greece, Vietnam and Iran. ${ }^{33} 424446$ Unlike many other studies, T2DM featured as the leading cause of total morbidity cost in the GCC countries (online supplementary table S15). This is unique to GCC where all but Oman are among the top 10 countries with the highest diabetes prevalence worldwide. ${ }^{53}$ Diabetes is more common in GCC countries due to several reasons, including high prevalence of obesity up to $48 \%$ in men and women ${ }^{54}$; fast epidemiological transition due to oil discovery, modernisation and globalisation ${ }^{405}$; and high consanguinity rate, which may amplify genetic factor. ${ }^{56}$ Chronic respiratory diseases were the second leading cause of smokingattributable morbidity costs.

Analysis by gender showed that the highest proportion of indirect cost was related to men's smoking habit. This could be explained by men's higher smoking prevalence ${ }^{39}$ and higher employment rates compared with women. ${ }^{43}$ Analysis by age group showed that indirect cost is lower for younger and older age groups, because employment-to-population ratio and YLD are lower than middle age groups, while for the younger, the deaths are lower too. Additionally, our study showed that the cost borne by the age group 30-34 years was higher for SHS than for active smoking. This could be due to young cohorts being exposed to SHS early in childhood, with the ill-effects of SHS exposure occurring at younger ages compared with active smoking.

\section{Strengths and limitations}

Our study has some limitations. First, owing to lack of local availability of several types of good quality data, we used proxies, which may have biassed our results. To estimate smoking-attributable 
fraction of healthcare costs, we used mortality data. This may have led to an underestimation of smoking-attributable healthcare expenditures. Second, a further underestimation of the cost may have resulted from not including non-healthcare costs of transportation to healthcare providers, informal care, property losses from fires caused by smoking, cost of cleaning up cigarette butts, business expenses to hire and train replacements for sick smokers; or not including indirect costs, such as the value of lost household production. Third, the economic cost of smoking among women is likely to be underestimated because woman tobacco use may be under-reported as a socially unacceptable practice. Finally, in the GBD study, a correlation among different risk factors has been taken into consideration only for the general category 'tobacco' which included smoking, SHS and smokeless tobacco. To assess whether we have overestimated total cost by calculating the economic cost of smoking and SHS separately, we re-estimated the economic cost of smoking using data of the general category 'tobacco'. There was only a slight change in the results.

In general, lack of good data is an issue in studies of the economic cost of tobacco use. Goodchild et al, ${ }^{20}$ for example, used data from 44 countries to estimate a relationship between smoking-attributable fraction of health expenditure and smokingattributable death rate. Then, they used this estimate to get an approximate calculation of the direct cost of active smoking in 108 countries, for which data on smoking-attributable fraction of health expenditure did not exist, including the GCC countries. Moreover, existing estimates of costs are difficult to compare as studies use different datasets, data sources, methodologies, discount factor for the estimation of mortality cost, a different set of tobacco-related diseases, and owing to inclusion or not of SHS.

Our study, nonetheless, has several strengths. It is the first study for the six GCC countries, covering a population of almost 52 million, to detail the economic cost of smoking including SHS by gender, age and disease for indirect cost. It also includes a larger group of diseases than many other published studies. Further, it is, to our knowledge, the first study that illustrates the contribution of smoking to the colossal burden of diabetes among countries that are overburdened by T2DM. ${ }^{53}$

\section{CONCLUSION}

The economic cost of smoking and SHS in the GCC countries is estimated to be relatively low compared with other high-income countries where the tobacco epidemic is more advanced. Given that the majority of healthcare cost resulting from tobacco use falls on national health systems that are fully funded by stateowned institutions, GCC governments are in urgent need to act on the scourge of tobacco.

Despite the recent introduction of regulations banning smoking in indoor public places, implementation of such bans, especially in waterpipe cafés, remains partial and poses a significant challenge for the national authorities. Implementing 100\% smoke-free indoor public places in all GCC countries would also require stronger political will among decision-makers.

To curb tobacco use, until recently, the GCC countries relied solely on import duties. Between 2016 and 2019, all except Kuwait implemented a new harmonised excise tax on all tobacco products, which led to doubling of their prices. In addition, in 2017 , a 5\% value-added tax was imposed on all tobacco products in Saudi Arabia, the UAE and Bahrain. Although the recent introduction of tax reforms and national tobacco control laws will contribute to curbing the tobacco epidemic, such measures need to be implemented synergistically with other evidencebased policies, such as effective health warnings including plain packaging of tobacco products (already introduced in Saudi Arabia), offering cessation services to active tobacco users and regular monitoring of tobacco use.

\section{What this paper adds}

- The economic cost of smoking has been determined in many countries, especially high-income countries, but only a small number of studies have estimated the economic cost of secondhand smoke (SHS).

- With the tobacco industry's focus shifted to areas with less comprehensive tobacco control measures, the trend in daily tobacco smoking is increasing and the tobacco epidemic is escalating in the Arabian Gulf Cooperation Council (GCC) countries.

- There are no studies focused specifically on estimating the economic cost of smoking and SHS exposure in the GCC countries.

- This paper estimated the economic cost of smoking and SHS exposure in the six GCC countries by source of expenditure (direct cost), gender, age and disease (indirect cost), including a larger number of smoking-related diseases than in most cost studies.

- The total cost was estimated to be $1.04 \%$ of the combined gross domestic product, with $20.4 \%$ of it being due to SHS.

- The highest percentage of direct cost was government health spending, the highest proportion of indirect cost resulted from smoking in men and middle-aged people, and the main causes were cardiovascular diseases (total mortality cost) and type 2 diabetes mellitus (total morbidity cost).

Contributors All authors have contributed to the development of this research work and manuscript. They contributed to study concept, study design, data collection, data analysis, scientific write up and literature review. All authors have reviewed the final draft manuscript and approved it.

Funding This work is part of the research project 'Tobacco Economics in the GCC countries', funded by the Gulf Health Council, the executive arm of the Council of Ministers of Health at GCC countries.

Competing interests None declared.

Patient consent for publication Not required.

Provenance and peer review Not commissioned; externally peer reviewed.

Data availability statement Data are available on reasonable request. All data relevant to the study are included in the article or uploaded as supplementary information. Further data would be available on request to Gulf Health Council. Data include details of study protocols, statistical analysis plans and extensive background statistical analysis conducted.

Open access This is an open access article distributed in accordance with the Creative Commons Attribution Non Commercial (CC BY-NC 4.0) license, which permits others to distribute, remix, adapt, build upon this work non-commercially, and license their derivative works on different terms, provided the original work is properly cited, appropriate credit is given, any changes made indicated, and the use is non-commercial. See: http://creativecommons.org/licenses/by-nc/4.0/.

\section{ORCID iD}

Yahya M Al-Farsi http://orcid.org/0000-0002-0302-7132

\section{REFERENCES}

1 World Health Organization. Tobacco fact sheet No. 339. Available: http://www.who. int/mediacentre/factsheets/fs339/en/ [Accessed Jun 2015].

2 World Bank. Curbing the epidemic, governments and the economics of tobacco control. Washington D.C: The World Bank, 1999.

3 World Health Organization. Tobacco: key facts. Available: https://www.who.int/newsroom/fact-sheets/detail/tobacco [Accessed 29 Dec 2019]. 
4 Ambrose JA, Barua RS. The pathophysiology of cigarette smoking and cardiovascular disease: an update. J Am Coll Cardiol 2004;43:1731-7.

5 Csordas A, Bernhard D. The biology behind the atherothrombotic effects of cigarette smoke. Nat Rev Cardiol 2013;10:219-30.

6 Holay MP, Paunikar NP, Joshi PP, et al. Effect of passive smoking on endothelial function in: healthy adults. J Assoc Physicians India 2004;52:114-7.

7 NTP (National Toxicology Program). Report on carcinogens. 14th edition. Research Triangle Park, NC: U.S. Department of Health and Human Services, Public Health Service, 2016

8 MacNee W. Pathology, pathogenesis, and pathophysiology. BMJ 2006;332:1202-4.

9 Pan A, Wang Y, Talaei M, et al. Relation of active, passive, and quitting smoking with incident type 2 diabetes: a systematic review and meta-analysis. Lancet Diabetes Endocrinol 2015;3:958-67.

10 Hurley S, Winstanley M. Musculoskeletal diseases. In: Scollo M, Winstanley M, eds. Tobacco in Australia: facts and issues. Melbourne: Cancer Council Victoria, 2015.

11 Bedno SA, Jackson R, Feng X, et al. Meta-Analysis of cigarette smoking and musculoskeletal injuries in military training. Med Sci Sports Exerc 2017:49:2191-7.

12 Li LF, Chan RLY, Lu L, et al. Cigarette smoking and gastrointestinal diseases: the causal relationship and underlying molecular mechanisms (review). Int J Mol Med 2014;34:372-80.

13 Durazzo TC, Mattsson N, Weiner MW, et al. Smoking and increased Alzheimer's disease risk: a review of potential mechanisms. Alzheimers Dement 2014;10:S122-45.

14 Zhang X, Kahende J, Fan AZ, et al. Smoking and visual impairment among older adults with age-related eye diseases. Prev Chronic Dis 2011;8:A84.

15 Sacks JJ, Nelson DE. Smoking and injuries: an overview. Prev Med 1994;23:515-20.

16 Makate M, Whetton S, Tait RJ, et al. Tobacco cost of illness studies: a systematic review. Nicotine Tob Res 2020:22:458-65.

17 Lightwood J, Collins D, Lapsley H, et al. Estimating the costs of tobacco use. In: Jha P, Chaloupka FJ, eds. Tobacco control in developing countries. Oxford: Oxford University Press, 2000.

18 Rehm J, Baliunas D, Brochu S, et al. The costs of substance abuse in Canada 2002: highlights. Available: https://www.ccsa.ca/sites/default/files/2019-05/ccsa-011332 2006.pdf [Accessed 31 Dec 2019].

19 Ekpu VU, Brown AK. The economic impact of smoking and of reducing smoking prevalence: review of evidence. Tob Use Insights 2015;8:TUI.S15628-35.

20 Goodchild M, Nargis N, Tursan d'Espaignet E. Global economic cost of smokingattributable diseases. Tob Control 2018;27:58-64.

21 WHO Framework Convention on Tobacco Control (WHO FCTC). Implementation review database. Available: https://untobaccocontrol.org/impldb/

22 Moh'd Al-Mulla A, Abdou Helmy S, Al-Lawati J, et al. Prevalence of tobacco use among students aged $13-15$ years in health ministers' Council/Gulf cooperation Council member states, 2001-2004. J Sch Health 2008;78:337-43.

23 GBD 2015 Tobacco Collaborators. Smoking prevalence and attributable disease burden in 195 countries and territories, 1990-2015: a systematic analysis from the global burden of disease study 2015. Lancet 2017;389:1885-906.

24 World Health Organization. Who global report on trends in prevalence of tobacco smoking 2000-2025. Geneva: World Health Organization, 2018.

25 AlBedah AMN, Khalil MKM. The economic costs of tobacco consumption in the Kingdom of Saudi Arabia. Tob Control 2014;23:434-6.

26 World Health Organization. Economics of tobacco toolkit: assessment of the economic costs of smoking. Available: https://apps. who.int/iris/handle/10665/44596 [Accessed 3 Dec 2019].

27 Rice DP, Hodgson TA, Kopstein AN. The economic costs of illness: a replication and update. Health Care Financ Rev 1985;7:61-80.

28 Rice DP. Cost of illness studies: what is good about them? Inj Prev 2000;6:177-9.

29 Institute for Health Metrics and Evaluation. Global burden of disease study 2017. Available: http://vizhub.healthdata.org/gbd-compare/ [Accessed 15 Feb 2019].

30 Yang L, Sung H-Y, Mao Z, et al. Economic costs attributable to smoking in China: update and an 8-year comparison, 2000-2008. Tob Control 2011;20:266-72.

31 John RM, Sung H-Y, Max W. Economic cost of tobacco use in India, 2004. Tob Control 2009:18:138-43.
32 Max W, Rice DP, Sung $\mathrm{H}$, et al. Valuing human life: estimating the present value of lifetime earnings, 2000. Available: https://escholarship.org/uc/item/82d0550k [Accessed 18 Nov 2018].

33 Koronaiou K, Delipalla S. The economic cost of tobacco smoking and secondhand smoke in Greece: musculoskeletal disorders the leading contributor to smokingrelated morbidity. Tob Prev Cessat 2019;5:39.

34 World Health Organization. Who guide to cost effectiveness analysis. Geneva: World Health Organization, 2003. https://www.who.int/choice/publications/p_2003_ generalised_cea.pdf

35 Institute of Health Metrics and Evaluation. Financing global health visualization. Available: http://vizhub.healthdata.org/fgh/ [Accessed 15 Feb 2019].

36 International Monetary Fund. World economic and financial surveys: world economic outlook database. Available: https://www.imf.org/external/pubs/ft/weo/2018/02/ weodata/index.aspx [Accessed 15 Dec 2018].

37 World Health Organization. Global health observatory data Repository. Available: http://apps.who.int/gho/data/node.main.LIFECOUNTRY?lang=en [Accessed 15 Dec 2018].

38 International Labour Organization. Employment-to-population ratio by sex and age and employment by sex and age. Available: https://www.ilo.org/shinyapps/ bulkexplorer7/?lang=en\&segment=indicator\&id=EMP_DWAP_SEX_AGE_RT_A [Accessed 15 Jan 2019].

39 World Health Organization. Who global report on trends in prevalence of tobacco use 2000-2025. 3rd edition. Geneva: World Health Organization, 2019.

40 Metz HC. Persian Gulf states: a country study. Available: http://countrystudies.us/ persian-gulf-states/14.htm [Accessed 31 Dec 2019].

41 Nargis N, Nyamurungi K, Baine SO, et al. The health cost of tobacco use in Uganda. Health Policy Plan 2017;32:1153-60.

42 Rezaei S, Karami Matin B, Hajizadeh M, et al. Economic burden of smoking in Iran: a prevalence-based annual cost approach. Asian Pac J Cancer Prev 2017;18:2867-73.

43 Shediac R, Samman H. Meeting the employment challenge in the GCC: the need for a holistic strategy. Abu Dhabi: Booz \& Company, 2010.

44 Bolin K, Lindgren B, Smoking LB. Smoking, healthcare cost, and loss of productivity in Sweden 2001. Scand J Public Health 2007;35:187-96.

45 Sung H-Y, Wang L, Jin S, et al. Economic burden of smoking in China, 2000. Tob Control 2006;15 Suppl 1:i5-11.

46 Hoang Anh PT, Thu LT, Ross H, et al. Direct and indirect costs of smoking in Vietnam. Tob Control 2016;25:96-100.

47 Sung $\mathrm{H}-\mathrm{Y}$, Chang L-C, Wen Y-W, et al. The costs of smoking and secondhand smoke exposure in Taiwan: a prevalence-based annual cost approach. BMJ Open 2014:4:e005199

48 Awan KH, Hussain QA, Khan S, et al. Accomplishments and challenges in tobacco control endeavors - Report from the Gulf Cooperation Council countries. Saudi Dent J 2018:30:13-18.

49 Hassounah S, Rawaf D, Khoja T, et al. Tobacco control efforts in the Gulf cooperation Council countries: achievements and challenges. East Mediterr Health $J$ 2014;20:508-13

50 Al-Lawati JA, Al-Thuhli Y, Qureshi F. Measuring Secondhand smoke in Muscat, Oman. Sultan Oaboos Univ Med J 2015:15:e288-91.

51 World Health Organization. Who air quality guidelines for particulate matter, ozone, nitrogen dioxide, and sulphur dioxide. Available: http://www.who.int/phe/health topics/outdoorair/outdoorair_agg/en/ [Accessed 14 Jul 2014].

52 Institute for Health Metrics and Evaluation (IHME). Country profiles. Available: http:// www.healthdata.org/results/country-profiles [Accessed 1 Jan 2020].

53 The World Bank. Diabetes prevalence (\% of population ages 20 to 79 ). Available: https://data.worldbank.org/indicator/SH.STA.DIAB.ZS [Accessed 1 Jan 2020].

54 Al-Lawati JA, Jousilahti PJ. Prevalence and 10-year secular trend of obesity in Oman. Saudi Med J 2004;25:346-51.

55 Al-Lawati JA, Al Riyami AM, Mohammed AJ, et al. Increasing prevalence of diabetes mellitus in Oman. Diabet Med 2002;19:954-7.

56 AlRubeaan K. Why three GCC countries are on the top ten countries for prevalence of diabetes: a close look into epidemiology, psychosocial and genetic factors. J Diabetes Metab 2014:5:10. 